\title{
Biotechnology guidelines
}

SIR-Tim Reardsley's article on the recently issued US biotechnology guidelines (Nature 322, 398; 1986) indirectly implies that this association has expressed the belief that the exemption of well-defined non-coding regulatory sequences from the administration's regulatory proposal should be removed. This is not our position. The Industrial Biotechnology Association (IBA) testified at the congressional hearing that Beardsley reported on and our statement supported the exemption contained in the proposed policy for biotechnology regulation.

We believe that many people have misinterpreted the nature and extent of the exemption for non-coding regulatory sequences. We have neither in public nor in private advocated its removal from the regulatory policy statement. IBA believes that a good case can be made for its inclusion and intends to address the issue in comments to the regulatory agencies.

Richard D. Godown

Industrial Biotechnology Association,

2115 East Jefferson Street,

Rockville, Maryland 20852, USA

SIR-The article by Tim Beardsley on the biotechnology guidelines (Nature 322, $398 ; 1986)$ inaccurately implies that the Association of Biotechnology Companies (ABC) wants the exemption of welldefined non-coding regulatory sequences removed from the US regulatory agencies' biotechnology proposal, published on 26 June 1986. On the contrary, ABC believes that removal of the exclusions would be scientifically indefensible. The concepts embodied in the definition for this exemption are derived from years of evolution of the National Institutes of Health (NIH) Recombinant DNA Guidelines. Those guidelines recognized, on the basis of creditable scientific data, that the splicing of DNAs that were "well characterized and free from harmful sequences" could be exempted from the guidelines, or at least that the required level of physical containment could be reduced.

The Association of Biotechnology Companies, representing 165 members worldwide, believes that the proposed biotechnology regulatory policies will evolve, as the NIH guidelines have, into less stringent ones as more understanding and knowledge is obtained. The removal of the exclusions, as your article proposes, would create an avalanche of unnecessary paperwork for government and industry and cannot be justified scientifically.

The article therefore did not accurately represent $A B C$ 's views, nor, I believe, those of the Industrial Biotechnology Association.

The headline "Regulations please nobody", taken out of context, also raises concern by conveying an overly negative impression. ABC supports the publication of the US biotechnology regulatory proposals. We recognize that it will be an evolving document, as were the $\mathrm{NIH}$ guidelines. Those areas, language, definitions or rules in the guidelines that $\mathrm{ABC}$ finds inappropriately burdensome can be ameliorated through comments, testimony and encouraging academic investigators to speak out. $\mathrm{ABC}$ also recognizes that no document will be entirely noncontroversial, given Jeremy Rifkin's strategy of appealing to the emotionality of the biotechnology issues.

The Association of Biotechnology Companies calls upon all interested parties to establish a constructive dialogue rather than seek to polarize interests. For the benefits of biotechnology to be achieved with minimal risks, a partnership between the public, the government and industry must be developed to cut through the emotionality, misconceptions and negativity that have been raised about biotechnology debate.

Bruce F. MACKLER Association of Biotechnology Companies, 1220 L Street NW, Suite 615,

Washington, $D C 20005, U S A$

- The false impression that industry organizations are critical of the exemption from special review for noncoding sequences is due to an ambiguity introduced in the editing. In the form of words originally used by Tim Beardsley, it was clear that the critical opinions are held privately by some industry spokesmen.-Editor, $\mathrm{Na}$ ture.

\section{AIDS in Africa}

SIR-Concern about the effects of the epidemic of acquired immune deficiency syndrome (AIDS) has related predominantly to the developed countries, but AIDS is a disease affecting people everywhere and in developing countries, such as those of central Africa, coping with AIDS presents particularly difficult problems.

In the developed world, extra money from government can be grafted onto a health service with an established infrastructure, which operates alongside charities, a sophisticated research capacity and an efficient local government. Furthermore, in such an environment, government can legislate about aspects of management and can gather essentially confidential information and use it to advise on therapy.

In developing countries, there is a very different social and economic environment. Many of the hospitals still run short of essential drugs and diagnostic reagents, and disposable needles and syringes are commonly re-used. Infant mortality remains at 10 per cent in the first year mainly through preventable causes such as measles and diarrhoea. Even communication can be a problem because of a shortage of paper.

If resources are so stretched now, it is logical to assume that even the slightest reduction in the money available for the provision of basic health could have the most serious of consequences. AIDS stands to deplete and divert resources vital for basic health services. Health departments could, of course, argue that AIDS is incurable and refuse to spend money on prolonging patients' lives. It is difficult to know how much might be saved but it should be borne in mind that the average AIDS patient costs the British National Health Service $£ 10,000$. But even if this policy were to be considered, AIDS would still divert large sums of money because there would remain a need to confine the disease: it would cost several million pounds to mount public information campaigns, to provide disposable needles and syringes and to monitor blood donors.

A rigid policy of containment rather than treatment is, in any case, unworkable. If the disease spreads, as it has in parts of Uganda where 2,500 people have already died and an estimated 30 per cent of the population are affected, then health workers dealing with the patients will be unable to withhold help. Whatever policy is adopted, it is impossible to know at the beginning of treatment whether a sickly child has been infected by an AIDSpositive mother, or whether a patient who develops malaria or tuberculosis does so because of impaired immunity.

The equations that have been used for determining health economics will now need to include an AIDS factor. That factor might be relatively small in the developed world, but elsewhere it may prove a drain on resources so large that basic health services are undermined.

There is, however, little prospect that the extra resources needed can come from the developing countries, so if the richer countries do not provide them, nobody will. Developed countries cannot stand by and allow AIDS to devastate, and at worst destabilize, central Africa, and later parts of South America and possibly Asia. There is an urgent and compelling need for the governments and charities of the developed world to provide support (and this will have to be vast) for the developing countries, both to underpin conventional health provision and to help to contain this treacherous epidemic. There must be no delay.

Joe COLlier Department of Clinical Pharmacology, St George's Hospital Medical School, Cranmer Terrace, London SW17 ORE, UK

Joe Collier is a World Health Organization Consultant on the Essential Drugs Programme in Tanzania. 